\title{
Structure and seasonal changes in atmospheric boundary layer on coast of the east Antarctic continent
}

\author{
BIAN Lingen $^{1 *}$, ZOU Han ${ }^{2}$, LIN Zhong ${ }^{1}$, ZHANG Dongqi ${ }^{1}$, Annette Rinke ${ }^{3} \&$ Klaus Dethloff ${ }^{3}$ \\ ${ }^{1}$ Chinese Academy of Meteorological Sciences, Beijing 100081, China; \\ ${ }^{2}$ Institute of Atmospheric Physics, Chinese Academy of Sciences, Beijing 100029, China; \\ ${ }^{3}$ Alfred Wegener Institute for Polar and Marine Research, Potsdam 14473, Germany
}

Received 17 June 2013; accepted 8 August 2013

\begin{abstract}
The temperature, humidity, and vertical distribution of ozone in the Antarctic atmospheric boundary layer(ABL) and their seasonal changes are analyzed, by using the high-resolution profile data obtained during the International Polar Year 2008 to 2009 at Zhongshan Station, to further the understanding of the structure and processes of the ABL. The results show that the frequency of the convective boundary layer in the warm season accounts for $84 \%$ of its annual occurrence frequency. The frequency of the stable boundary layer in the cold season accounts for $71 \%$ of its annual occurrence frequency. A neutral boundary layer appears rarely. The average altitude of the convective boundary layer determined by the parcel method is $600 \mathrm{~m}$; this is 200 to $300 \mathrm{~m}$ higher than that over inland Antarctica. The average altitude of the top of the boundary layer determined by the potential temperature gradient and humidity gradient is $1200 \mathrm{~m}$ in the warm season and $1500 \mathrm{~m}$ in the cold season. The vertical structures of ozone and specific humidity in the ABL exhibit obvious seasonal changes. The specific humidity is very high with greater vertical gradient in the warm season and very low with a lesser gradient in the cold season under $2000 \mathrm{~m}$. The atmospheric ozone in the ABL is consumed by photochemical processes in the warm season, which results in a slight difference in altitude. The sub-highest ozone center is located in the boundary layer, indicating that the ozone transferred from the stratosphere to the troposphere reaches the low boundary layer during October and November in Antarctica.
\end{abstract}

Keywords coast of the east Antarctic continent, structure of the atmospheric boundary layer, ozone, seasonal changes

Citation: Bian L G, Zou H, Lin Z, et al. Structure and seasonal changes in atmospheric boundary layer on coast of the east Antarctic continent. Adv Polar Sci, 2013, 24:138-145, doi: 10.3724/SP.J.1085.2013.00138

\section{Introduction}

The Arctic and Antarctic regions are the main cold sources that allow global atmospheric circulation. Numerical models of weather and climate exhibit uncertainty in terms of present and future simulations and forecasts ${ }^{[1]}$. One of the most important reasons for such uncertainty is the lack of sufficient understanding of the interaction between icesnow-ocean and the atmosphere, and the error in the boundary layer parameterization scheme in the polar regions. Therefore, observational research should be conducted into the processes of the boundary layer in polar regions, particularly in Antarctica, to provide the basis for

* Corresponding author (email: blg@cams.cma.gov.cn) the improvement and correction of the boundary layer parameterization scheme $\mathrm{e}^{[2-5]}$. Measured data of the Antarctic atmospheric boundary layer (ABL) are quite poor because of the adverse climatic conditions and transport difficulties. Most previous studies have analyzed and simulated turbulent parameters based on data from turbulent flux and profile experiments on the near-surface layer in summer or from Antarctic weather stations ${ }^{[6-7]}$. Atmospheric stratification occurs mostly in the stable structure because of the relatively weak solar radiation and low temperature in the Antarctic continent. Thus, most studies have focused on the stable structure in the Antarctic ${ }^{[8]}$. Handorf et al. ${ }^{[9]}$ identified that the $\mathrm{ABL}$ is very shallow in stable conditions over the Antarctic ice sheet. Mastrantonio ${ }^{[10]}$ reported that development of the convective boundary layer is similar to that at middle latitudes. The altitude of the boundary layer 
is 100 to $300 \mathrm{~m}$ over the Antarctic ice sheet during the polar day, according to the sonar sounding data obtained at Dome C. Under different stability conditions, the obviously abnormal atmospheric humidity is related to the dynamic processes of the ABL and the diffusion processes of the transition layer. King et al. ${ }^{[11]}$ indicated that despite basically similar amounts of solar radiation recorded in summer at both Dome C inland and Halley Station located on the coast of the Antarctic continent, the diurnal variation of the ABL exhibits an obvious difference. A significant diurnal pattern is exhibited in the structure of the ABL at Dome $\mathrm{C}$, whereas no such pattern exists at Halley. Van and Broeke ${ }^{[12]}$ revealed that the thermal property of the underlying surface with different terrains and landforms in the Antarctic coastal area is more complicated. The climatic characteristics of the Antarctic ABL and related research have been documented $^{[13-17]}$ in many experiments. For example, the twenty-fifth Chinese National Antarctic Research Expedition(25th CHINARE) performed balloon soundings of atmospheric temperature, humidity, and ozone partial pressure at Zhongshan Station during 2008-2009. These soundings provide a basis for the analysis of the ABL. This paper examines the structural characteristics of the $\mathrm{ABL}$ based on high-resolution sounding data. The seasonal variations exhibited by the boundary layer at Zhongshan Station in eastern Antarctica are also analyzed.

\section{Instruments and data description}

The observation site is located on the coast about $100 \mathrm{~m}$ away from the water's edge in the East Antarctic continent. Its climatic conditions are influenced by a complex interplay of katabatic winds, topographic structures, and oceanic influences with 58 polar days and polar nights, annually. Vaisala GPS RS-80-15 wireless electro-meteorological sondes and ECC(Electrochemical Concentration Cell, EN-SCI Company, USA) type $2 \mathrm{Z}$ electrochemistry ozone sondes, configured by the EN-SCI Company, were adopted to perform the detection of a number of atmospheric elements: Pressure, ozone, temperature, relative humidity, and wind speed and direction. To ensure the reliability of the observed data, the sensors were calibrated in accordance with the requirements of the observation standards(EN-SCI Company) prior to each launch. Soundings were performed once a week, which generated 58 soundings from 1 February 2008 to 15 February 2009 . The specified time of the operation was 15:00 local time. During the observational period, only two soundings failed because of bad weather. The measurement accuracy of the instruments and detailed soundings have been published by $\mathrm{Smit}^{[18]}$. The quality of the data has been checked by the T-lnp diagram method for each profile and no irregularities were found ${ }^{[19]}$.

\section{Types of atmospheric boundary layer}

As sounding data were obtained only once a week, this research examines the characteristics of the seasonal change of the ABL at Zhongshan Station. The ABL is usually classified into one of three types: Convective boundary layer (CBL), stable boundary layer (SBL), and neutral boundary layer (NBL), based on atmospheric stability(buoyancy effects) and the dominant mechanism of turbulence generation $^{[20]}$. In theory, the CBL forms at the surface and grows upwards during the day as the ground is heated by the sun and convective currents transfer heat upwards into the atmosphere. The SBL forms at the surface and grows upwards, usually at night or in winter, as heat is extracted from the atmosphere's base in response to longwave radiative heat loss from the ground. SBLs can also form when warm air is advected over a cold surface or over melting ice. The NBL exists in either unsaturated air, when the environmental lapse rate equals the dry adiabatic rate, or in saturated air, when the environmental lapse rate equals the moist adiabatic lapse rate. In practice, the boundary layer type can be determined in terms of the potential temperature profile.

In this study, between the surface and $3000 \mathrm{~m}$, a decrease of potential temperature with height defines a CBL; an increase of potential temperature with height defines an SBL, and constant potential temperature with height determines an NBL.

The observational data of the ABL are obtained from the soundings conducted at Zhongshan Station at approximately 15:00 local time. A strong CBL often appears at mid-latitudes. However, in the Antarctic, the structure of the ABL displays diverse trends due to the low atmospheric temperature. Table 1 shows the frequency of occurrence of the different types of $\mathrm{ABL}$, determined from 56 potential temperature profiles. The CBL appeared 25 times, accounting for $45 \%$ of all data. The CBL appeared 21 times during the warm season (October to March), accounting for $84 \%$ of its total frequency of occurrence, and only 4 times during the cold season (April to September). The SBL appeared 28 times, accounting for $50 \%$ of all data. The SBL appeared 20 times during the cold season, accounting for $71 \%$ of its total frequency of occurrence and 8 times during the warm season. The NBL appeared only three times throughout the year, accounting for $5 \%$ of all data. The statistics in Table 1 show that the ABL is mainly convective in the warm season and stable in the cold season. The NBL appears rarely during the year. However, the seasonal variation of the ABL type is related to the regime of solar radiation and turbulent motion, as well as to the synoptic weather system on the coast of the eastern Antarctic continent. As described by Li et al. ${ }^{[21]}$, the sensible heat flux at Zhongshan Station during the summer half-year(from October to February) is positive, whereas it is negative during the winter half-year(from March to September).

\subsection{Convective boundary layer}

The reason for the appearance of the CBL during the warm season is possibly related to solar radiation and the underlying surface conditions. Zhongshan Station is built on the 
Antarctic coast on an oasis area where solar radiation is enhanced gradually during late spring when the snow begins to melt. There is no surface snow cover from December to March. A large amount of radiation is absorbed by the atmosphere in the form of turbulent heat flux. The surface layer then allows easy, but unstable atmospheric stratification. Figure 1 shows that on 15 February, a super adiabatic layer appeared because of the potential temperature of the surface layer, which decreased with an increase in altitude. A middle mixed layer and interlayer appeared above the super adiabatic layer. The specific humidity and relative humidity both exhibited an obvious gradient at the top of the boundary layer. The sky was cloudless that day, which was not conducive to the absorbance of solar energy by the surface. Underlying turbulence developed to form the CBL. The change in the partial pressure of ozone, caused by the increase in height, indicates that ozone in the ABL in sum- mer is approximately $50 \%$ lower than that in winter. This result reveals the role of photochemical reactions in ozone reduction. Ozone partial pressure shows an obvious decrease with height(close to $300 \mathrm{~m}$ ) in summer, but not in winter.

Table 1 Occurrence frequency of the types of boundary layer at Antarctic Zhongshan Station (Unit: Time)

\begin{tabular}{cccccccccccccc}
\hline Month & 1 & 2 & 3 & 4 & 5 & 6 & 7 & 8 & 9 & 10 & 11 & 12 & total \\
\hline Sounding number & 4 & 7 & 3 & 3 & 4 & 4 & 4 & 5 & 5 & 8 & 4 & 5 & 56 \\
CBL & 4 & 4 & 0 & 0 & 1 & 2 & 0 & 0 & 1 & 5 & 4 & 4 & 25 \\
SBL & 0 & 3 & 1 & 3 & 3 & 2 & 4 & 4 & 4 & 3 & 0 & 1 & 28 \\
NBL & 0 & 0 & 2 & 0 & 0 & 0 & 0 & 1 & 0 & 0 & 0 & 0 & 3 \\
\hline
\end{tabular}

CBL: convective boundary layer; SBL: stable boundary layer; NBL: neutral boundary layer.

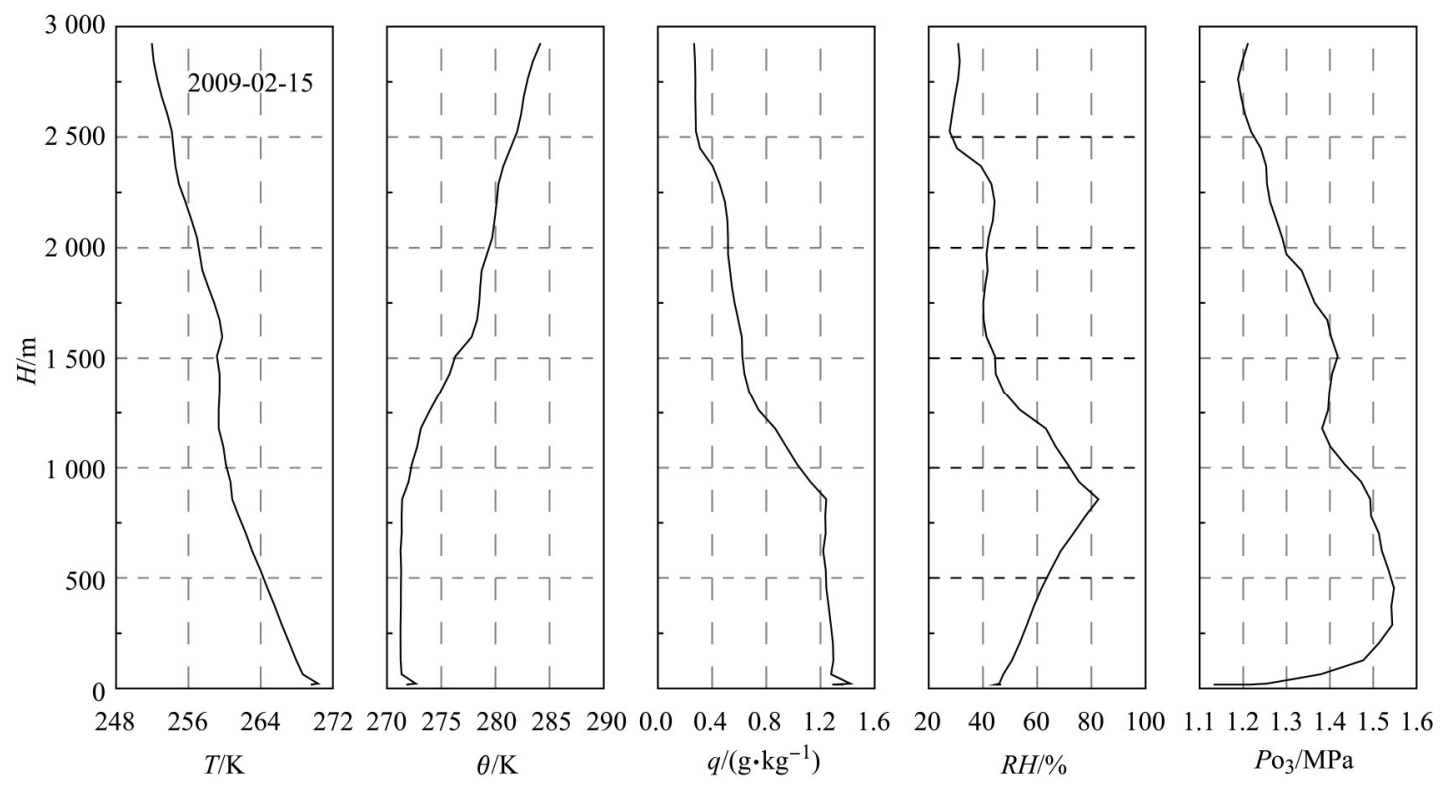

Figure 1 Vertical profiles of temperature $(T)$, moist potential temperature $(\theta)$, specific humidity $(q)$, relative humidity $(R H)$, and ozone partial pressure $\left(\mathrm{P}_{3}\right)$ in unstable atmospheric stratification at Zhongshan Station on 15 February 2009.

\subsection{Stable boundary layer}

The structure of the SBL appeared mainly during the cold season, under conditions of continuous snow and very weak solar radiation, which occurred during, before, and after the polar night. Figure 2 shows a typical profile of the SBL during the cold season. The potential temperature below $3000 \mathrm{~m}$ increased with height on 17 April 2008, forming the obvious structure of a stable ABL. It was a cloudy day, which was not conductive to the development of a CBL. Therefore, an SBL structure formed. An inversion layer appeared at between 300 and $400 \mathrm{~m}$ above the boundary layer. Correspondingly, the values of specific humidity and relative humidity also exhibited a strong gradient.

Although convective stratification occurred primarily during the warm season, stable stratification also occurred under different weather conditions. An SBL structure appeared on 24 December and 16 February 2008(Figure 2). December 24 was a cloudy day with snow and strong wind. Thick clouds resulted in radiative cooling from the surface to form the SBL. However, an SBL structure also appeared on 16 February, which was a sunny day. This could have been caused by the SBL stratification forming because of the descent of warm advection on the upper boundary layer. The change in ozone partial pressure with an increase in height is shown in Figure 2. The figure also shows the change in characteristics of the photochemical reaction under the conditions of an SBL in the two cases. Ozone partial pressure decreases significantly with an increase in height on sunny days, but decreases from the surface layer only gradually on cloudy days owing to the weak photochemical reaction. 

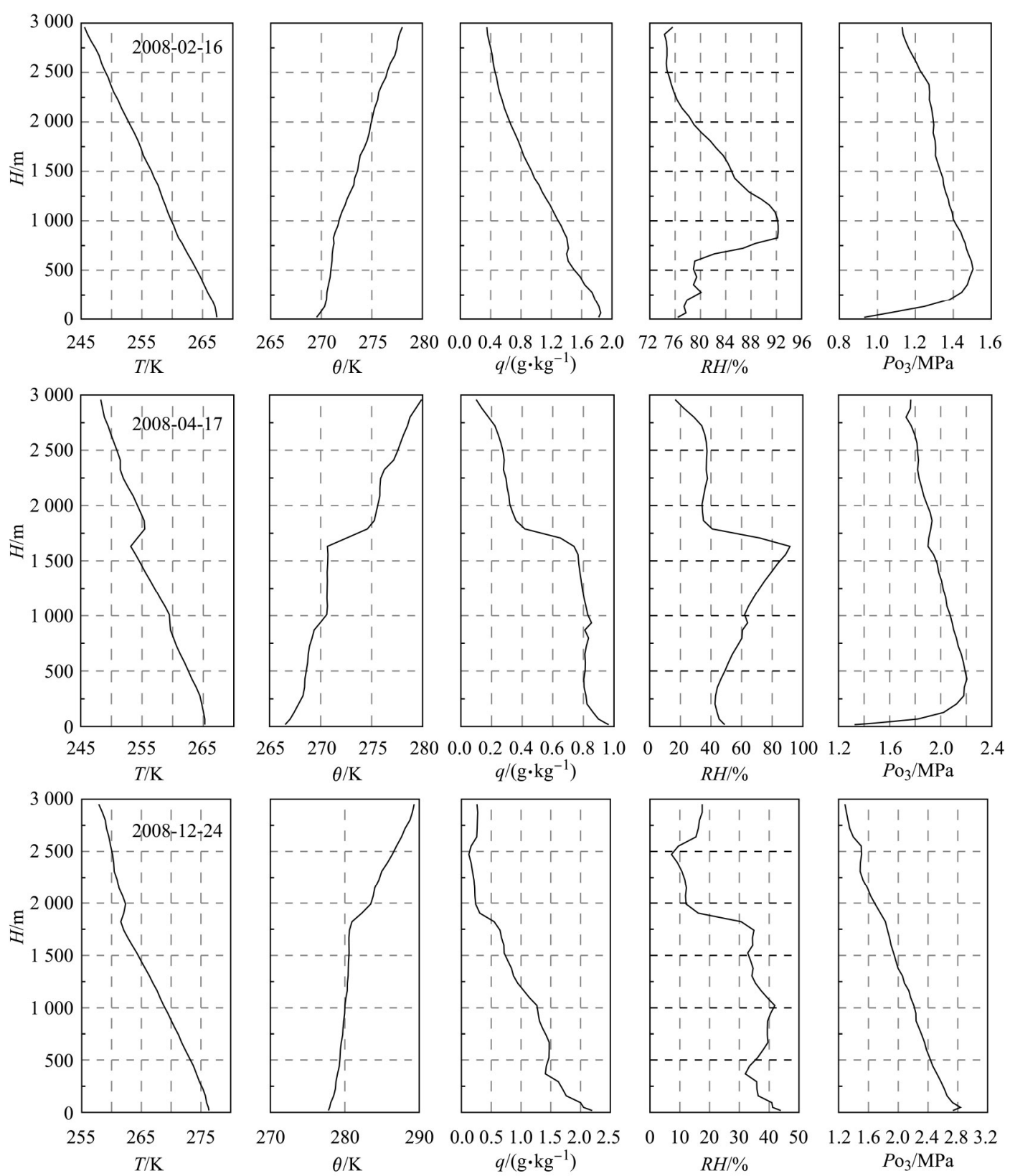

Figure 2 Vertical profiles of temperature $(T)$, moist potential temperature $(\theta)$, specific humidity $(q)$, relative humidity $(R H)$, and ozone partial pressure $\left(P_{\mathrm{O}_{3}}\right)$ in the typical stable boundary layer at Zhongshan Station on 16 February, 17 April, and 24 December, 2008.

\subsection{Neutral boundary layer}

The NBL structure appeared rarely during the year. Figure 3 shows the vertical profiles of temperature, specific humidity, potential temperature, relative humidity, and ozone partial pressure in the near-NBL(within $3000 \mathrm{~m}$ ) on 29 March and 21 August 2008. The potential temperature profile indicates that these three near-NBL structures all appeared during the transition from a CBL to an SBL, wherein the potential temperature change in the surface layer on 29 March was based on the type of the SBL. These three days were cloudy, which was conductive to the formation of the NBL. The change in specific humidity and ozone with an increase in height exhibited obvious differences on two days. Specific humidity and ozone partial pressure decreased with an increase in height from the ground on 29 March, indicating the effects of radiation and photochemical reaction. Specific humidity exhibited an inversion phenomenon below $200 \mathrm{~m}$ on 21 August. Ozone partial pressure increased significantly with an increase in height and reached its maximum at approximately $500 \mathrm{~m}$, reflecting the effect of inversed humidity in conditions without photochemical reaction or solar radiation in winter(Figure 3). This phenomenon indicates that humidity and ozone in the surface layer were not combined fully in the neutral atmospheric stratification defined by the potential temperature under specific atmos- 
pheric conditions.

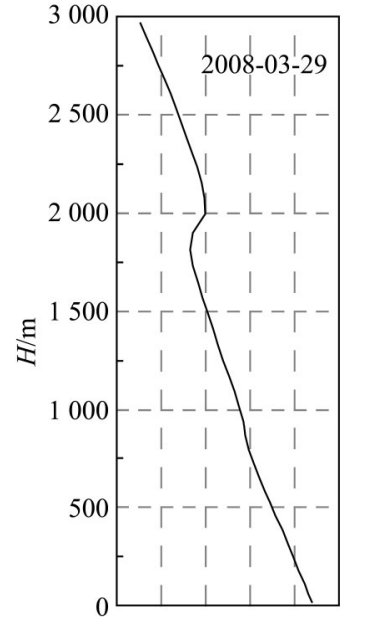

245250255260265270265

$T / \mathrm{K}$

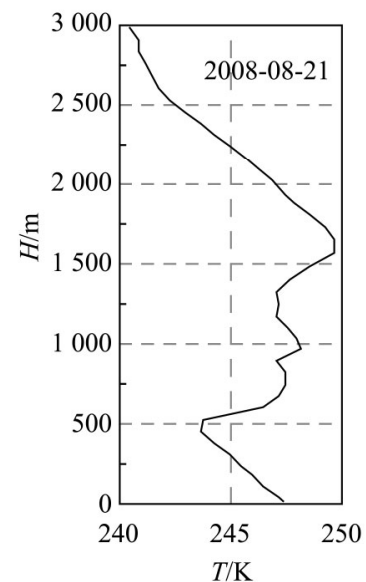

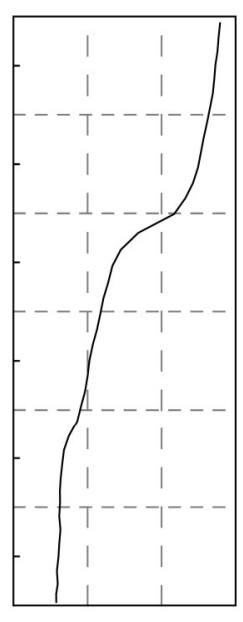

$270 \quad 275$

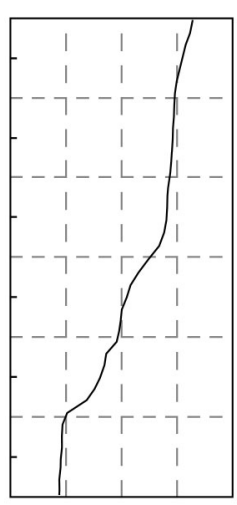

$240250 \quad 260270280$
$\theta / K$

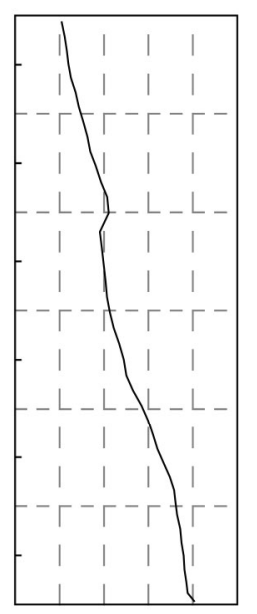

$\begin{array}{llllllll}80 & 0.0 & 0.4 & 0.8 & 1.2 & 1.6 & 2.0\end{array}$ $q /\left(\mathrm{g} \cdot \mathrm{kg}^{-1}\right)$

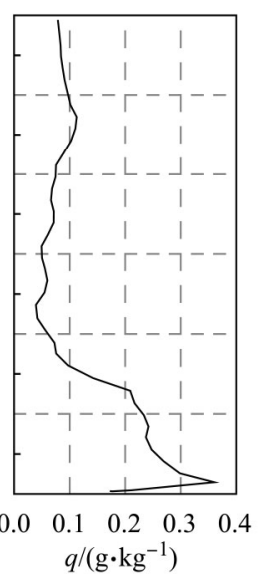

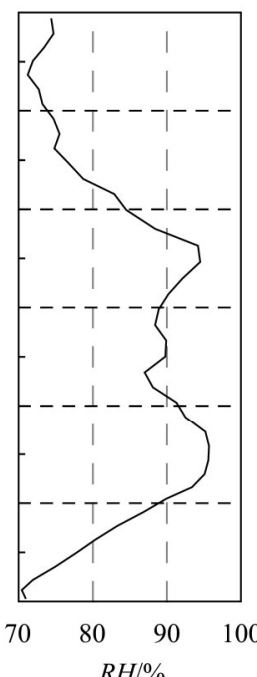

RH/\%

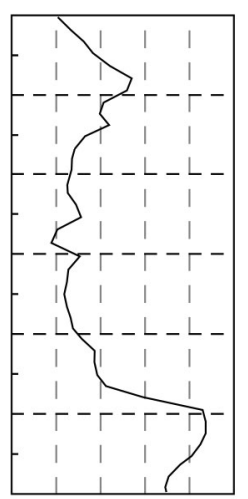

$\begin{array}{lllllll}0 & 20 & 40 & 60 & 80 & 100 & 0.81 .21 .62 .02 .42 .83 .2\end{array}$

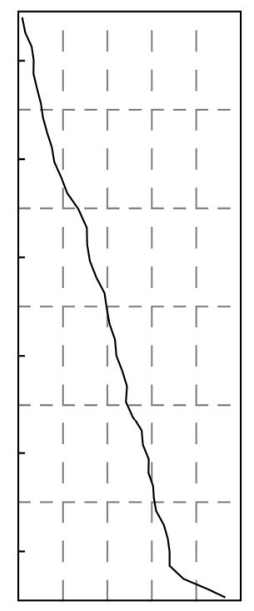

$\mathrm{PO}_{3} / \mathrm{MPa}$

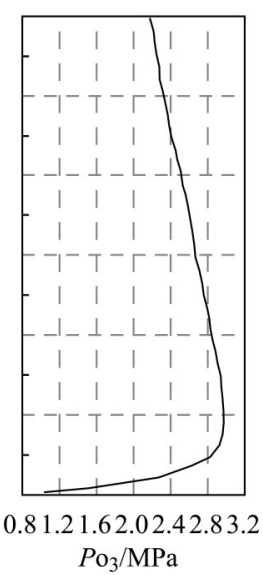

Figure 3 Vertical profiles of temperature $(T)$, moist potential temperature $(\theta)$, specific humidity $(q)$, relative humidity $(R H)$, and ozone partial pressure $\left(\mathrm{PO}_{3}\right)$ in the typical neutral boundary layer structure at Zhongshan Station on 29 March and 21 August 2008.

\section{Seasonal change of the boundary layer structure}

The altitude of the ABL is an important parameter in $\mathrm{ABL}$ model parameterization and research on air pollution diffusion. Certain errors were expected in determining the height of the ABL because of the multilayer temperature inversion structure. The ABL height was analyzed quantitatively by applying the two most commonly used methods to determine the boundary layer height. First, where the height of the inversion base is considered as the boundary layer height $^{[22]}$ and second, where the maximum height of the temperature gradient is assumed to correspond to the $\mathrm{ABL}$ height $^{[23]}$. A near-surface-layer temperature inversion was formed because of the strong radiative cooling effect of the snow and ice underlying the surface layer. From the first method, the boundary layer height was determined to be close to the formation; thus, the strongest inversion layer was selected for the determination. Figure 4 shows the altitude of the CBL at Zhongshan Station during the entire year.
A CBL was rarely observed at Zhongshan Station in autumn and winter. From September onwards, the altitude of the CBL increased gradually with the increase in solar radiation. The average altitude of the CBL was approximately $600 \mathrm{~m}$, and its minimum altitude was approximately $200 \mathrm{~m}$. The maximum altitude was over $1000 \mathrm{~m}$. The CBL on the Antarctic coast was higher than that at Dome $\mathrm{C}$ in inland Ant$\operatorname{arctica}^{[5]}$. The altitude of the boundary layer top was determined by the strongest potential temperature gradient and humidity gradient, as shown in Figure 5. The altitude of the boundary layer top was consistent during spring and summer. However, the altitude of the boundary layer top determined by the humidity gradient was approximately $200 \mathrm{~m}$ higher than that determined by the potential temperature gradient in autumn and winter. The accuracy of the humidity observations was lower than that of the temperature observations under low temperature conditions. The altitude of the CBL is shown in Figure 4. The altitude determined by the potential temperature gradient was higher than that determined by the humidity gradient, which indicates that the potential temperature gradient method is more accurate 
in determining the boundary layer altitude.

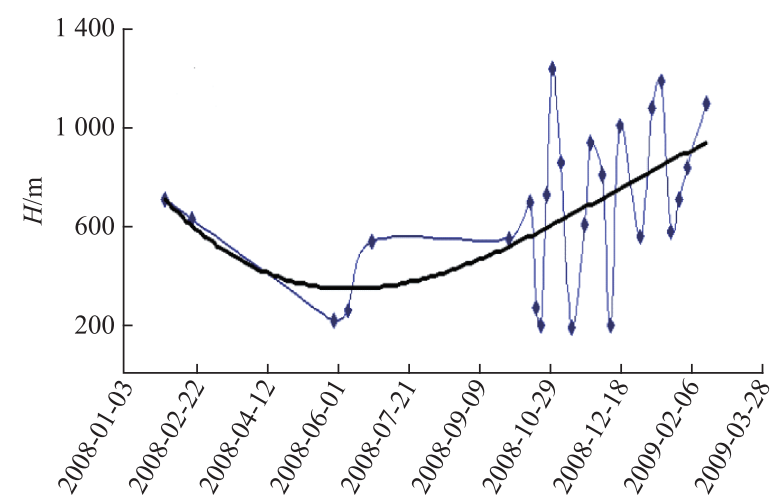

Figure 4 Seasonal change in the altitude of the convective boundary layer at Zhongshan Station from February 2008 to February 2009 . The solid line is the fitting line.

Figure 5 shows that the seasonal change in boundary layer altitude is not obvious. The SBL appeared mainly during autumn and winter and its altitude was higher than that of the CBL in summer. The altitude of the SBL was approximately $1500 \mathrm{~m}$ during autumn and winter and below $1000 \mathrm{~m}$ in summer.

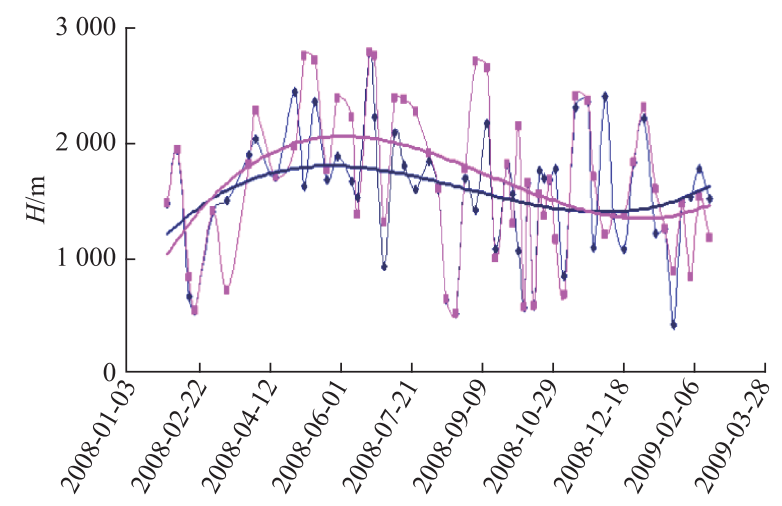

Figure 5 Time series of the altitude of the boundary layer top at Zhongshan Station from February 2008 to February 2009. The solid line is the fitting line.

\section{Seasonal change of ozone in the boundary layer}

There are periods of about two months of polar days and two months of polar nights annually, at Zhongshan Station, which determine the seasonal change in the characteristics of the various elements of the ABL. Figure 6 provides a cross-sectional view of seasonal change for the profiles of temperature, specific humidity, and ozone below $3000 \mathrm{~m}$. In summer, especially on polar days, the photochemical reaction caused by the strong radiation consumed a part of the ozone in the boundary layer(Figure 6). This state of depletion is more obvious as altitude increases. The temperature profile represents the characteristics of the CBL.
Boundary layer ozone increased from the surface layer with an increase in height during other seasons, especially in winter. The peak value appeared at approximately $500 \mathrm{~m}$, which indicates that without ozone, the ABL maintained a relatively high concentration. The high concentration was maintained even without the photochemical reaction in winter.
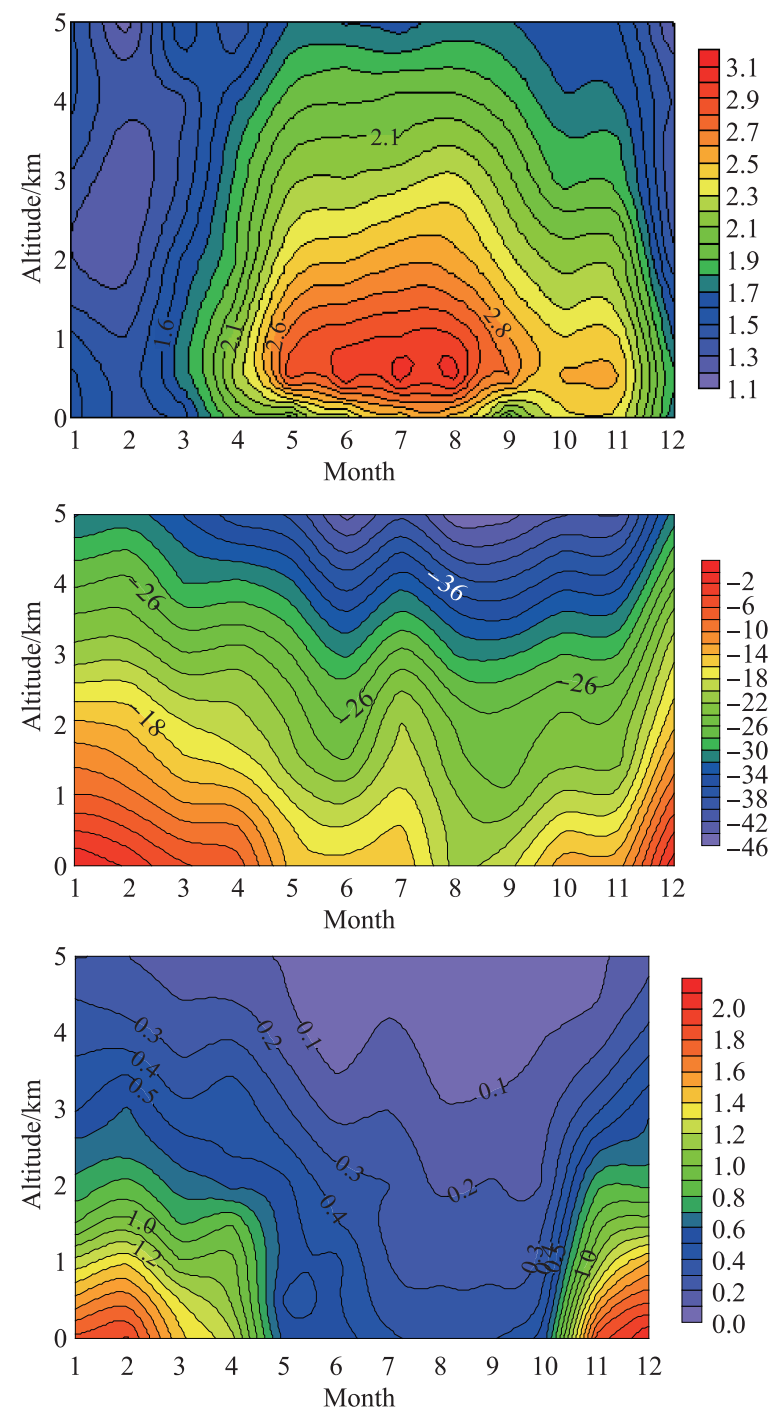

Figure 6 Vertical profiles of ozone partial pressure(upper), temperature(middle), and specific humidity(lower; $\mathrm{g} \cdot \mathrm{kg}^{-1}$ ) below $5 \mathrm{~km}$ at Zhongshan Station in 2008.

The temperature profile exhibits inversion layers of different intensities. Considering the different weather conditions, the altitude of the inversion layer ranged from hundreds of meters to thousands of meters, and displayed the atmosphere stratification of the SBL in winter. During the warm season(October to March), specific humidity and its gradient of change(with an increase in altitude less than $2000 \mathrm{~m}$ ) were larger than those during the cold season (April to September). This difference could have been caused by climatic characteristics. The melting of surface 
snow and sea ice in the water around the station in summer led to an increase in specific humidity in the boundary layer. The situation was reversed in winter, at which time the station and the water around it were covered by thick snow. The Antarctic katabatic winds blew strongly in the boundary layer. In addition, the specific humidity at the station maintained an extremely low value because of the effect of the dry and cold air from inland.

Aside from the high content of ozone in the boundary layer from June to August, the period of the Antarctic ozone hole(September to November) also produced a sub-higher ozone value center(Figure 6) in the boundary layer. This occurrence could have been caused by an increase in ultraviolet radiation in the troposphere causing $\mathrm{NO}_{\mathrm{x}}$ content to increase in the boundary layer, resulting in an increase of ozone content in spring, when an obvious reduction in ozone occurs in the stratosphere. The movement of ozone is obstructed by the strong polar vortex in winter. The high-value ozone center below the stratospheric level appeared approximately one month later than that in the upper level of the stratosphere, indicating that ozone in the troposphere during winter is mostly due to transmission from the upper atmosphere. The vertical structure of atmospheric temperature indicates that no obvious heat tropopause was observed in winter. This condition is conducive to the transmission of ozone from the stratosphere to the boundary layer.

\section{Conclusion}

The above analysis provides a preliminary understanding of the structure of the ABL and ozone variation, as well as their seasonal change, during the International Polar Year 2008 to 2009 at Zhongshan Station in Antarctica. The CBL appeared mainly during the warm season, accounting for $84 \%$ of its annual frequency of occurrence. The SBL appeared during the cold season, accounting for $71 \%$ of its annual frequency of occurrence. Such seasonal variation of the $\mathrm{ABL}$ is related to the regime of solar radiation and surface conditions, as well as the local prevailing katabatic wind. On average, the altitude of the CBL during the warm season was $600 \mathrm{~m}$; the lowest altitude was $200 \mathrm{~m}$, and the highest altitude was over $1000 \mathrm{~m}$. The lowest altitude of the CBL was similar to that in the Antarctic inland during summer. The top of the boundary layer, determined by the potential temperature gradient and humidity gradient, was $1200 \mathrm{~m}$ during the warm season and $1500 \mathrm{~m}$ during the cold season, which shows that the ABL is very deep. In addition to uncertainties with the method, larger uncertainty exists related to the katabatic wind from the inland ice sheet. However, more work is required (i.e., numerical modeling) to elucidate the mechanism. Vertical structures of both ozone and specific humidity within the ABL exhibited clearly seasonal changes. During the warm season, specific humidity below $2000 \mathrm{~m}$ was extremely high; in the cold season, it was very low with a small gradient. Part of the ozone in the $\mathrm{ABL}$ was consumed by photochemical reaction due to the strong radiation during the Antarctic warm season, resulting in the slight change in the gradient of ozone with an increase in altitude. The obvious peak of ozone appeared close to $500 \mathrm{~m}$, which related to the structure of the SBL. A sub-high ozone center was observed in the boundary layer in the Antarctic during October and November, indicating that ozone transferred from the stratosphere to the troposphere had reached the boundary layer. The pattern of variation in the structure and ozone of the ABL on the coast of the eastern Antarctic continent requires more data and further study to confirm these results.

Acknowledgments This work is supported by the Chinese Polar Environment Comprehensive Investigation \& Assessment Programmes(2011-2015). All the members of the 24th and 25th CHINAREs are acknowledged for their great help in collecting the data.

\section{References}

1 IPCC. Working Group I Contribution to the Fourth Assessment Report of the Intergovernmental Panel on Climate Change. Cambridge: Cambridge University Press, 2007, 130-336.

2 Argentini S, Viola A, Sempreviva A M, et al. Summer boundary-layer height at the plateau site of Dome C, Antarctica. Bound-Layer Meteor, 2005, 115: 409-422, doi:10.1007/s10546-004-5643-6.

3 Lin Z, Bian L G, Ma Y F, et al. Turbulent parameters of the near surface layer over the ice sheet nearby Zhongshan Station, east Antarctica. Chinese J Polar Res, 2009, 21(3): 221-233(in Chinese).

4 Qu S H, Gao D Y, Zhou H. Atmospheric boundary layer structure and turbulent flux transfer over the Zhongshan Station area Antarctica. Chinese J Polar Sci, 1997, 8(2): 79-88.

5 Genthon C, Town M S, Six D, et al. Meteorological atmospheric boundary layer measurements and ECMWF analyses during summer at Dome C, Antarctica. J Geophys Res, 2010, 115, D05104, doi:10.1029/2009 JD012741.

6 Zhou M Y, Zhang Z H, Zhong S Y, et al. Observations of near-surface wind and temperature structures and their variations with topography and latitude in East Antarctica. J Geophys Res, 2009, 114, D17115, doi:10. 1029/2008JD011611.

7 Rinke A, Ma Y F, Bian L G, et al. Evaluation of atmospheric boundary layer-surface process relationships in a regional climate model along an East Antarctic traverse. J Geophys Res, 2012, 117, D09121, doi:10. 1029/2011JD016441.

8 King J C, Turner J. Antarctic Meteorology and Climatology, Cambridge Atmospheric and Space Sciences Series. Cambridge: Cambridge University Press, UK, 1997: 409.

9 Handorf D, Bink N J, Vugts H F. The stable atmosphere boundary layer over an Antarctic Ice Sheet. Boun-Layer Meteor, 1999, 91: 165-189.

10 Mastrantonio G, Malvestuto V, Argentini S, et al. Evidence of a convective boundary layer developing on the Antarctic Plateau during the summer. Meteorol Atmos Phys, 1999, 71: 127-132.

11 King J C, Argentini S A, Anderson P S. Contrasts between the summertime surface energy balance and boundary layer structure at Dome $\mathrm{C}$ and Halley stations, Antarctica. J Geophys Res, 2006, 111, D02105, doi:10. 1029/2005JD006130.

12 Van As D, van den Broeke M R. Causes of variability in the summertime Antarctic boundary-layer climate. Internat J Clim, 2007, 27: 1735-1751.

13 Mahesh A, Walden V P, Warren S G. Radiosonde measurements in strong inversions: Correction for thermal lag based on an experiment at the South Pole. J Atmos Oceanic Technol, 1997, 14: 45-53. 
14 Van As D, van den Broeke M R. Structure and dynamics of the summertime atmospheric boundary layer over the Antarctic Plateau: 2. Heat, moisture, and momentum budgets. J Geophys Res, 2006,111, D07103, doi:10.1029/ 2005JD006956.

15 Van As D, van den Broeke M R, Reijmer C H, et al. The summer surface energy balance on the high Antarctic Plateau. Boun-Layer Meteor, 2005,115: 289-317, doi:10.1007/s10546-004-4631-1.

16 Parish T R, Cassano J J. The role of katabatic winds on the Antarctic surface wind regime, Mon Weather Rev, 2003, 131: 317-333.

17 Van As D, van den Broeke M R, Broeke M R. Evaluation of temperature and wind over Antarctica in a Regional Atmospheric Climate Model using 1 year of automatic weather station data and upper air observations. J Geophys Res, 2005,110, D04103, doi:10.1029/2004JD005234.

18 Smit H G J. Assessment of the performance of ECC ozonesondes under quasi-flight conditions in the environmental simulation chamber: Insights from the Juelich Ozone Sonde Intercomparison Experiment (JOSIE). J
Geophys Res, 2007, 112, D19306, doi:10. 1029/2006JD007308.

19 Bian L G, Lin Z, Zhang D Q, et al. The vertical structure and seasonal changes of atmosphere ozone and temperature at Zhongshan Station over East Antarctica. China Earth Sci, 2012, 55(2): 262-270, doi:10.1017/ s11430-011-4355-2.

20 Stull R B. An introduction to boundary layer meteorology. Springer Netherland, 1988: 650-670.

21 Li S M, Wang X Q, Zhou M Y. A polar regions flux observation system and its application in the IPY global coordinated observation. Marine Forecasts, 2010, 27(1): 62-71(in Chinese).

22 Wyngaard J C, Lemone M A. Behavior of the refractive index structure parameter in the entraining convective boundary layer. J Atmos Sci, 1980, 37: 1573-1585.

23 Sullivan P P, Moeng C H, Stevens B, et al. Structure of the entrainment zone capping the convective atmospheric boundary layer. J Atmos Sci, 1998, 55: 3042-3064. 